\title{
Recommendations from the European Working Group for Value Assessment and Funding Processes in Rare Diseases (ORPH-VAL)
}

Lieven Annemans ${ }^{1}$, Ségolène Aymé ${ }^{2}$, Yann Le Cam ${ }^{3}$, Karen Facey ${ }^{4}$, Penilla Gunther ${ }^{5}$, Elena Nicod ${ }^{6}$, Michele Reni ${ }^{7}$, Jean-Louis Roux ${ }^{8}$, Michael Schlander ${ }^{9,10,11}$, David Taylor ${ }^{12}$, Carlo Tomino ${ }^{13}$, Josep Torrent-Farnell ${ }^{14}$,

Sheela Upadhyaya ${ }^{15}$, Adam Hutchings $^{16^{*}}$ (D) and Lugdivine Le Dez ${ }^{17}$

\begin{abstract}
Rare diseases are an important public health issue with high unmet need. The introduction of the EU Regulation on orphan medicinal products (OMP) has been successful in stimulating investment in the research and development of OMPs. Despite this advancement, patients do not have universal access to these new medicines. There are many factors that affect OMP uptake, but one of the most important is the difficulty of making pricing and reimbursement (P\&R) decisions in rare diseases. Until now, there has been little consensus on the most appropriate assessment criteria, perspective or appraisal process. This paper proposes nine principles to help improve the consistency of OMP P\&R assessment in Europe and ensure that value assessment, pricing and funding processes reflect the specificities of rare diseases and contribute to both the sustainability of healthcare systems and the sustainability of innovation in this field. These recommendations are the output of the European Working Group for Value Assessment and Funding Processes in Rare Diseases (ORPH-VAL), a collaboration between rare disease experts, patient representatives, academics, health technology assessment (HTA) practitioners, politicians and industry representatives. ORPH-VAL reached its recommendations through careful consideration of existing OMP P\&R literature and through a wide consultation with expert stakeholders, including payers, regulators and patients. The principles cover four areas: OMP decision criteria, OMP decision process, OMP sustainable funding systems and European co-ordination. This paper also presents a guide to the core elements of value relevant to OMPs that should be consistently considered in all OMP appraisals. The principles outlined in this paper may be helpful in drawing together an emerging consensus on this topic and identifying areas where consistency in payer approach could be achievable and beneficial. All stakeholders have an obligation to work together to ensure that the promise of OMP's is realised.
\end{abstract}

Keywords: Orphan medicinal products, Rare diseases, Pricing and reimbursement, Health technology assessment, Value assessment, Guidelines

\footnotetext{
* Correspondence: adam.hutchings@dolon.com

${ }^{16}$ Dolon Ltd, London, UK

Full list of author information is available at the end of the article
} 


\section{Background}

The European Union (EU) regulation on Orphan Medicinal Products (OMPs) EC 141/2000 has been vital for stimulating investment into OMP research and development (R\&D), furthering an EU-wide aim of ensuring that patients with rare diseases have equity of access to effective treatment [1, 2]. To date, the European Medicines Agency (EMA) has authorised 129 OMPs and 1,435 as yet unapproved products have OMP designation [3]. Rare diseases are an important public health issue and it is important that patients with these diseases have access to safe and effective therapies in the same way as others suffering from more common diseases [4]. Once regulatory authorisation has been granted to an OMP by the EMA, it is essential for patients to benefit from it within the shortest timeline and this should be consistent across Europe. Whether this goal is achieved is influenced by the pricing of these therapies and by the mechanisms used by national healthcare decisionmakers to assess, reimburse and fund them [1, 2, 4-7]. A 2009 study found that, of 43 EMA-approved OMPs, the proportion reimbursed varied from 56 to $91 \%$ across seven Western-European countries [1, 8]. Another evaluation of 10 European countries observed a difference in reimbursement between countries according to income level, with France, Netherlands and Denmark reimbursing $90 \%$ of 60 authorised OMPs, while Spain, Greece and Romania reimbursed only one-third [9].

P\&R processes for OMPs are particularly challenging due to the inherent characteristics of rare diseases and the scarcity of knowledge and expertise on the natural history of these conditions [10,11]. Clinical trial development is also complicated due to small and typically heterogeneous patient populations, resulting in difficulties in patient identification and recruitment, and lack of surrogate end-points to predict longer term outcomes [12]. Therefore health technology assessment (HTA) agencies often have to assess OMP value - the benefit from treatment for patients, healthcare systems and society - in the presence of evidential uncertainty $[10,11]$.

The small size of the target patient population - OMP regulation in Europe stipulates a prevalence of less than 5 in 10,000 [13] - means that the per-patient price of OMPs is higher than for medicines for more common conditions [14]. As a consequence, OMPs assessed in systems that use cost-effectiveness analysis have often failed to meet accepted thresholds, particularly where the prevalence is at the lower end of the spectrum of rare diseases $[11,15]$. Uncertainty about the true size of rare disease patient populations creates financial risk for payers and compounds broader concerns about the ongoing cost of funding the growing number of treatments for rare diseases $[5,16,17]$.
Some HTA bodies and payers have reacted to these challenges by creating supplementary OMP-specific assessment mechanisms (e.g. NICE Highly Specialised Technology Programme in England and the Life Savings Drugs Program in Australia) or by adapting existing P\&R processes (e.g. OMP special status in benefit assessments in Germany and the PACE process at the Scottish Medicines Consortium) $[18,19]$. More often, decisions regarding OMPs are made following the same process as for other medicines.

The diversity of P\&R pathways for OMPs across European countries can represent a challenge to all manufacturers of medicines, and this is particularly true for OMPs. While there is some consistency in the core clinical information considered by HTA agencies, there are considerable disparities in how data is interpreted, the use of economic analysis, the perspective of the evaluation and the extent to which patients and healthcare professionals (HCPs) are involved, amongst other factors [11, 18, 20, 21].

These differences in assessment methodology partly reflect a lack of consensus amongst policy makers on the optimal P\&R framework for OMPs and how to overcome the challenges that rare diseases represent to HTA agencies. Many European countries are reviewing P\&R processes for OMPs, providing an opportunity to seek closer alignment on the fundamental aspects of such systems [22, 23].

In this paper we propose nine principles to help improve the consistency of OMP P\&R in Europe and ensure that it reflects the inherent characteristics of rare diseases. The principles cover issues relating to value assessment, $P \& R$, and funding processes for OMPs, grouping them in four parts: decision criteria, decision processes, sustainable funding and European co-ordination.

Moreover, to help improve consistency in the decision criteria used to assess the value of OMPs between countries, we propose a set of core elements that together constitute the value of an OMP. This paper does not represent an attempt to define a single P\&R framework for European countries, but rather to propose underlying principles that should be common to all, regardless of the mechanism used in each country to make decisions.

The principles described herein are recommendations from the 15 authors of this article, who are designated as the European Working Group for Value Assessment and Funding Processes in Rare Diseases (ORPH-VAL). This Working Group is a collaboration between rare disease experts across seven European countries, including HTA practitioners, physicians, patient representatives, academics, politicians and industry representatives. A detailed description of each Working Group member's experience relevant to this topic is provided in the declaration section. The experts were selected to achieve a breadth of geographical and disciplinary perspective and 
based on their active involvement in the field of rare diseases and willingness to participate in the initiative on a voluntary basis. ORPH-VAL reached its recommended principles through an iterative process of assessment of existing OMP guidelines and frameworks, identification of core themes, formulation of draft principles, internal and external review, and subsequent refinement. The Working Group members participated in five workshops (two face to face, three via teleconference) between June 2015 and September 2016 (Fig. 1). Wherever possible, ORPH-VAL has built upon, or aligned with, outputs from existing initiatives in this area, such as the Mechanisms of Co-ordinated Access to Orphan Medicinal Products (MoCA-OMP) and EUnetHTA Joint Action 2.

The core elements of OMP value were selected from a systematic review of proposed frameworks for rare diseases and non-rare diseases [24]. Table 1 shows the frameworks reviewed by ORPH-VAL.

Elements of value proposed in the literature were presented to the Working Group according to the frequency of occurrence and grouped by theme (e.g. disease-related, clinical, economic) and by perspective (patient, healthcare system, society). From this starting point, ORPH-VAL members were split into two groups which separately prioritised the core elements, before seeking consensus between the groups. Two sets of elements were considered: 1) elements that inform on the intrinsic value of an OMP and as such should be accounted for by decision making committees during the deliberative process; 2) elements that are beyond product value but are likely to inform or influence the P\&R decision.

ORPH-VAL refined its principles through feedback from other European rare disease experts and stakeholders
(Fig. 1). A draft version of the principles was presented and debated during the EURORDIS Multi-Stakeholder Symposium on the 24th of February 2016. A public consultation of the draft principles was organised through EURORDIS and publicised through OrphaNews on the 22nd March 2016. Interested participants were invited to complete an online survey and provide their comments on the document. Finally, ORPH-VAL had an opportunity to present and discuss the principles with the MoCAOMP Group in September 2016. Feedback from all commentators was collated into themes for consideration by ORPH-VAL before being incorporated into a second draft of the principles. The nine principles are summarised in Fig. 2.

\section{Principles on OMP decision criteria}

PRINCIPLE 1: OMP assessment should consider all relevant elements of product value in an appropriate multi-dimensional framework

a) Decision-makers should consider OMP value from the perspective of patients, the healthcare system and wider society

b) While the choice of value elements that are used to assess OMPs should be country specific, ORPH-VAL has proposed a set of core elements that should be common to all health systems (Fig. 3)

c) HTA agencies and payers should make explicit which elements of value they prioritise, how the rarity of a disease influences their assessment, and how societal preferences are incorporated into their decisions

Rare diseases have particular characteristics beyond the small number of patients affected. They often impact patients from birth, affect multiple organ systems, are severely disabling, can greatly reduce life expectancy and impair physical and mental abilities [37, 38]. These

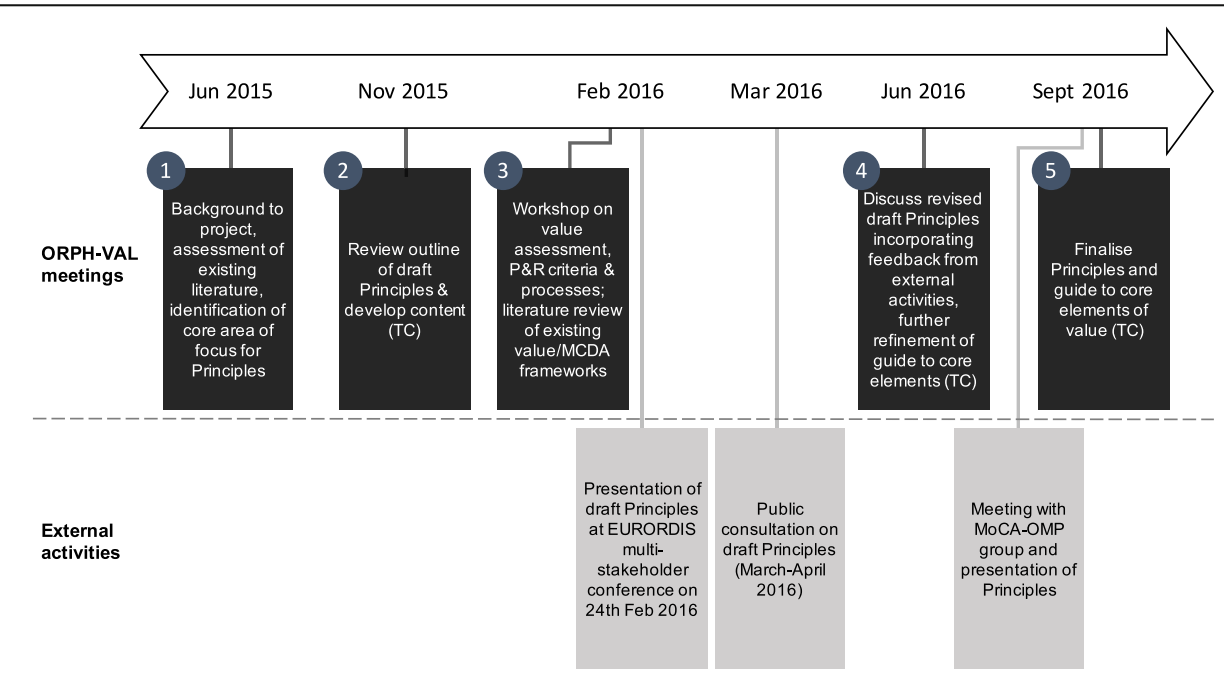

Fig. 1 Process through which the Principles were developed. MoCA-OMP: mechanism of coordinated access to orphan medicinal products; MCDA: multi-criteria decision analysis; P\&R: Pricing and reimbursement; TC: teleconference 


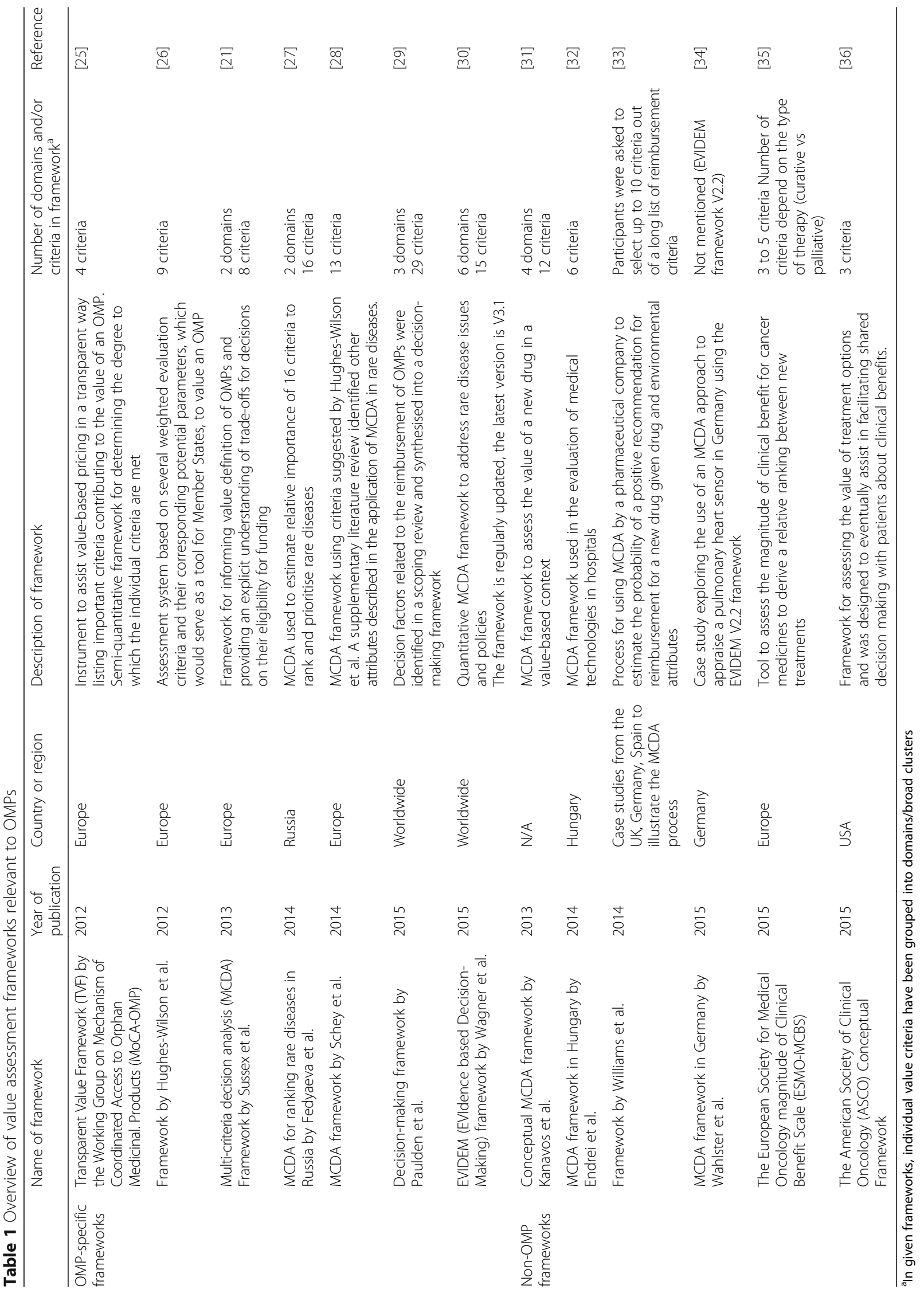




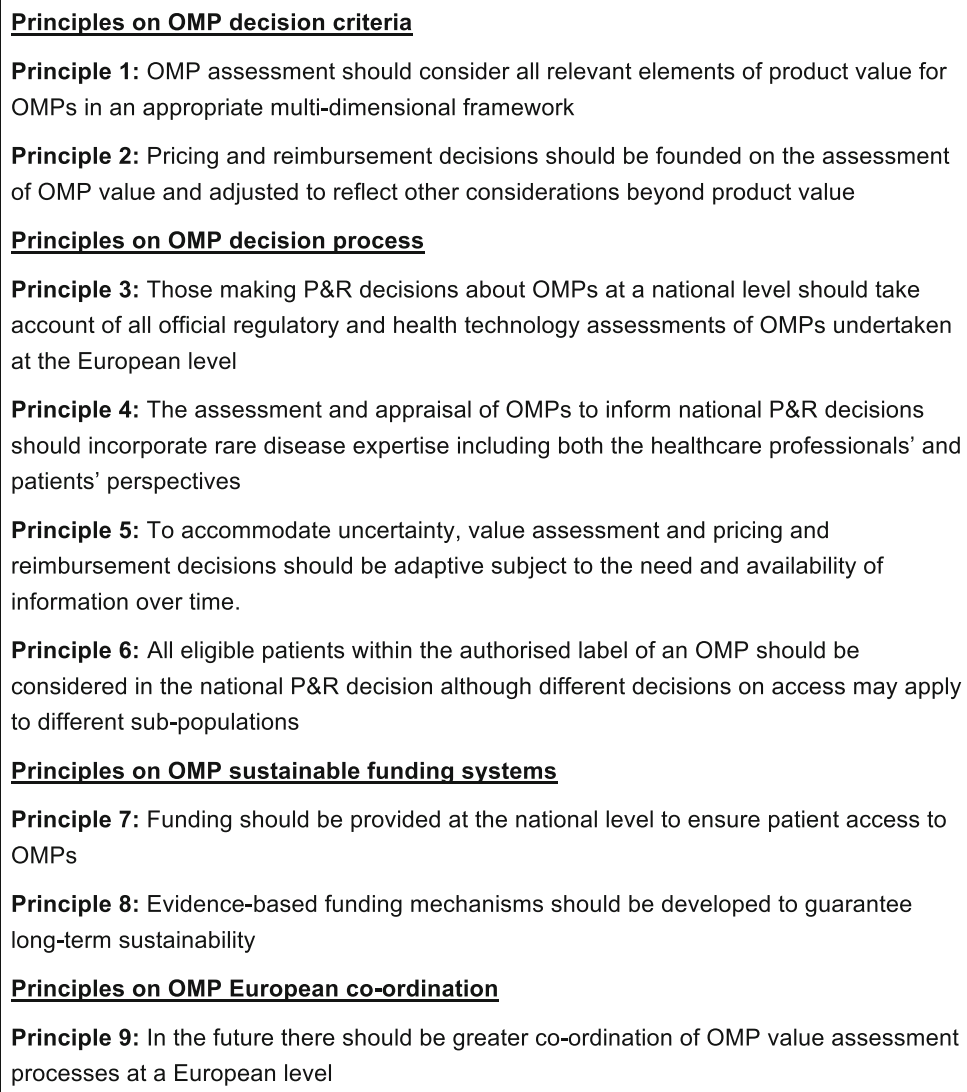

Fig. 2 Summary of Principles for value assessment and funding processes in rare diseases

impairments affect health-related quality of life (HRQoL) and can impact an individual's ability to benefit from education and secure employment [39]. In a survey of 2,500 patients with chronic diseases, patients with rare disorders had the worst experience in terms of loss of social and economic opportunities and of access to medical care [39].

Rare diseases also often have a disproportionate impact beyond the patient. Many rare diseases are genetic, meaning more than one member of a family can be affected [39]. Rare diseases also pose a considerable burden on caregivers [37, 39]. The severity of rare diseases means patients often require intensive care, usually from a family member, which reduces their ability to work. The lack of specialist support and information on the disease increases the burden for patients and their families. At a wider level, rare diseases require substantial healthcare and social care system resources [38, 40-42]. Given the multidimensional nature of the burden of rare diseases and the wide range of stakeholders affected, it is important that decision makers assess the value of OMPs holistically, including the perspectives of patients, the healthcare system and wider society (including family and carers).

The elements that are considered within $P \& R$ decisions vary across European countries [43]. ORPHVAL has proposed a set of core elements it believes should be common to all systems (Fig. 3; a detailed description of the elements and explanation of the terms used is included in Additional file 1). The elements described in Fig. 3 represent proposed domains of value. ORPH-VAL did not seek to define metrics for how these elements should be measured, nor value thresholds or weights indicating the relative importance of different elements. Such factors, which relate to the creation of societal value, should be informed by, and aligned with, societal preferences of the population in the respective country. While information on potential international variation in societal value judgments is still limited, there is a growing body of literature documenting the relevance and breadth of societal preferences $[44,45]$. 


\begin{tabular}{|c|c|c|}
\hline & ON & lue \\
\hline & Impact of Disease on & Impact of Treatment on \\
\hline \multirow[t]{2}{*}{ Patient level } & \multicolumn{2}{|c|}{$\begin{array}{l}\text { Survival / Life expectancy } \\
\text { Morbidity } \\
\text { Patient experience and health-related quality of life } \\
\text { Patient economic burden }\end{array}$} \\
\hline & Existing treatment options & $\begin{array}{c}\text { Side effects } \\
\text { Treatment convenience }\end{array}$ \\
\hline Healthcare system level & \multicolumn{2}{|c|}{$\begin{array}{l}\text { Healthcare system resources and budget } \\
\text { Healthcare system organisation }\end{array}$} \\
\hline Societal level & \multicolumn{2}{|c|}{$\begin{array}{l}\text { Family / Carer health-related quality of life } \\
\text { Family / Carer economic burden } \\
\text { Societal economic burden }\end{array}$} \\
\hline \multicolumn{3}{|c|}{ Considerations beyond OMP value } \\
\hline \multicolumn{3}{|c|}{$\begin{array}{l}\text { Rarity } \\
\text { - Budgetimpact } \\
\text { - Sustainability of innovation in rare diseases } \\
\text { Societal preferences }\end{array}$} \\
\hline \multicolumn{3}{|c|}{ Uncertainty of OMP value } \\
\hline $\begin{array}{l}\text { Quality of evidence } \\
\text { Uncertainty around value }\end{array}$ & \multicolumn{2}{|c|}{$\begin{array}{l}\text { neters } \\
\text { nexisting evidence base }\end{array}$} \\
\hline
\end{tabular}

Fig. 3 Guide to core elements of value relevant to pricing and reimbursement decisions in rare diseases. See Additional file 1 for glossary of terms on the core elements of value

With a recognition of the importance of transparency in the evaluation process, $P \& R$ frameworks should be clear about the elements of value that are considered within the value assessment process and their relative importance in determining the overall decision $[46,47]$. It should be explicit how these decisions are informed so as to ensure legitimacy and to provide clear guidance to OMP developers about the types of products that society wishes them to develop [48].

Multi-criteria decision analytic (MCDA) frameworks have been proposed for rare diseases [21, 25, 26, 29, 30]. These frameworks have the advantages of providing sufficient flexibility to incorporate all value elements of importance and, as shown in a pilot study of a rare disease MCDA framework, are capable of incorporating different stakeholder perspectives [21]. In contrast, where cost-effectiveness frameworks have been used to assess OMPs, they have often failed to be sufficiently flexible to capture all relevant elements and perspectives [49-51].

The OMP value assessment process, as described in Principle 1, should form the basis of $P \& R$ decisions. These two components - value assessment and P\&R appraisal - are often undertaken separately and consecutively in many European systems, such as in France and Germany [52, 53]. In order to translate an assessment of value into a $P \& R$ decision, it is necessary to interpret the added value generated by a new OMP relative to an appropriate price benchmark. The $P \& R$ decision should therefore consider the value for money of a new OMP in light of price precedents for other specialist medicines that offer comparable value. These comparator products should share similar fundamental characteristics to the

PRINCIPLE 2: Pricing and reimbursement decisions should be founded on the assessment of OMP value and adjusted to reflect other considerations beyond product value

a) Reimbursement decisions should be based on the product value delivered by an OMP as described in Principle 1

b) The price should, among other elements, be informed by considering the magnitude of the product value in light of price-value precedents for other specialist technologies and medicines

c) P\&R decisions should reflect the value that the EU attributes to OMPs through the incentives put in place to develop them

d) Beyond OMP value, P\&R status should be modulated to reflect other considerations, such as societal preferences, rarity, budget impact and sustainability of innovation in rare diseases

e) In countries where cost-effectiveness is applied to assess value for money, the incremental cost-effectiveness ratio (ICER) thresholds should be modulated to reflect:

- all specificities of rare diseases (including rarity, unmet therapeutic need and societal preferences)

- the need to maintain innovation in rare diseases

f) P\&R decisions should aim at contributing to the right balance between allowing sufficient revenue generation to incentivise new research investment in rare diseases and attract private funders, while maximising value for money for healthcare systems 
OMP under evaluation in respect to disease severity, number of patients and product attributes [5].

Beyond the value of the OMP, other considerations are relevant to $P \& R$ decisions, including the size of the expected budget impact (across all approved indications, if more than one) and societal preferences concerning the value of new treatments for a given rare disease [30, 47, 54-56].

The size of the patient population for an authorised treatment is an important consideration in $P \& R$ decision making. Rarer diseases are associated with greater evidential uncertainty compared with more common diseases as there is less information on the natural history of disease and smaller patient numbers in clinical trials [57]. Rarity is therefore pertinent to the consideration of the uncertainty around the value estimate. The size of the patient population is also a major determinant of the budget impact for payers and the revenue potential for manufacturers and thus is directly relevant to the $P \& R$ decision $[7,58]$. OMP legislation was an explicit recognition that incentives to invest in developing treatments for rare diseases are lower than for more common diseases (a smaller patient population results in a lower potential return on investment) [2, 59]. OMP pricing has subsequently been observed to be correlated with disease prevalence, with higher per patient prices in the rarest diseases [60]. Studies of societal preferences for funding treatments for rare diseases have not shown clear support for prioritising rarity alone in $P \& R$ decisions, however there is a preference for reducing inequalities in health outcomes [61-63]. Given that the degree of rarity directly affects the financial incentive to develop treatments in a given disease area, it is only possible to address health inequalities in small populations if rarity is taken into account.

Cost effectiveness analysis (particularly when restricted to a health service perspective) is not optimal for the assessment of OMPs, as the QALY fails to account for all of the core elements of value relevant to rare diseases [49-51]. If it is to be used to inform assessments of OMPs, the ICER thresholds should be modulated to reflect all the specificities of rare diseases as described in Fig. 3. Countries that use strict and non-modulated ICER thresholds to guide reimbursement decisions have a poor record of approving OMPs (e.g. Canada) [49]. For OMPs to be approved in systems using ICERs for decision making, payers will need to adopt variable thresholds at levels higher than that applied historically $[14,20]$.

In general, $\mathrm{P} \& \mathrm{R}$ decisions should balance the need to enable revenue generation to incentivise new research investment in rare diseases with the need to maximise value for money for healthcare systems. But OMPs prices should be such that all products that provide clinically meaningful added benefits (i.e. that are approved by the Committee for Orphan Medicinal Products [COMP]/EMA) are commercially feasible and incentivise continued investment in rare diseases. At the same time, the $P \& R$ decision must also consider the affordability of the expenditure and be aligned with the sustainability of healthcare system finances.

\section{Principles on OMP decision process}

To ensure consistency and alignment between Member States, avoid duplication of evaluations, and improve resource utilisation, $P \& R$ agencies should build on the official decisions and recommendations made for OMPs at a European level, tailoring and adapting these assessments to their local environment. Currently, the duplication of regulatory and HTA activities at a national level contributes to the lengthy and often variable access to OMPs across Member States [64].

Official decisions and recommendations include the COMP's assessment of significant benefit and prevalence, the EMA's European Public Assessment Report (EPAR) and the relative effectiveness assessments undertaken by the European network on

PRINCIPLE 3: Those making P\&R decisions about OMPs at a national level should take account of all official regulatory and health technology assessments of OMPs undertaken at the European level

a) National P\&R agencies should build on the decisions and recommendations at a European level, including

- The Committee for Orphan Medicinal Products (COMP)'s assessment of significant benefit and prevalence

- The EMA's European Public Assessment Report and Summary of Product Characteristics

- Relative effectiveness assessments undertaken by the European network for HTA

health technology assessment (EUnetHTA). Payers should also account for early conditional and exceptional marketing authorisations as well as the early scientific advice provided by the EMA. European legislation recommends Member States use COMP/ EMA assessments to guide and align national decision making, helping build on existing, central regulatory European assessments.

This approach offers several benefits. European-level health authorities have the greatest concentration of rare-disease expertise and, importantly, COMP offers specific rare disease guidance (conversely, national level assessment authorities are typically more generalised). This also ensures Member States can utilise clinical experts from the specialist centres across Europe [2, 4, 65]. Avoiding duplication of effort and reducing existing asymmetries in assessments may improve resource utilisation and, subsequently, reduce the time to OMP decision-making. 
While there is a need to ensure national assessments and decisions reflect the local population's needs, there is a strong argument that, in the case of rare diseases, the centralised knowledge, data and expertise that is pooled at the European level leads to stronger decision processes than those restricted to information available locally. Where central and national opinions differ, with contradictory conclusions, there is a need to acknowledge the importance of this and find consistency between assessments.

HCPs, patients (and their carers) should be involved in the value assessment (HTA) and appraisal (P\&R decision making) of OMPs, offering an important insight into the real-world experience of a rare disease $[5,29,66-71]$. The nature of rare diseases mean that the involvement of patient and physician experts is even more important than in assessments of treatments for non-rare diseases. There is often limited information on the natural history and burden of a rare disease, and current standard of care treatments may be poorly established with little evidence of effectiveness [72, 73]. These stakeholders can help authorities understand what outcomes are relevant in a disease and what level of improvement is clinically meaningful.

PRINCIPLE 4: The assessment and appraisal of OMPs to inform national P\&R decisions should incorporate rare disease expertise including both the healthcare professionals' (HCP) and patients' perspectives

a) HCPs and patients and their carers should be involved in the value assessment in the following ways:

- Disease-specific expert physicians (and other relevant academic specialists) should be involved from scoping of an assessment through to appraisal determination by the bodies that assess and appraise OMP

- Systematic representation of patient associations in meetings that assess and appraise OMPs

- Disease-specific patient representatives should be involved throughout the process and given appropriate training and support to contribute fully

HCPs and patients have the expertise and experience to discuss HRQoL, burden of disease and patient preferences [67, 74, 75]. Clinical experts and patients may also help interpret the relevance of trial data, where endpoints might be unusual or not validated in the disease in question. They can help assessment authorities understand why surrogate endpoints have been used and what they mean $[76,77]$.

In addition to trial design interpretation, clinical experts and patient groups can help inform estimates of prevalence and potential patient uptake on treatment. Patient associations have previously provided very accurate estimates of patients (e.g. the MPS
Society for elosulfase alfa in the UK [78]). Experts may also help to establish the natural history of the rare disease, its symptomology and burden, in the absence of observational data. For example, patient interviews and surveys have been instrumental in establishing knowledge about the ways in which rare diseases affect patients, their families and the costs they impose on wider society [79]. Finally, patients and HCPs can provide insights into the current patient treatment pathways and identify issues with current treatments and expectations from new therapies $[69,75,77]$.

The involvement of HCPs and patients in value assessment can be implemented in a variety of ways. For example, disease-specific expert physicians (and other relevant academic specialists) can input directly into the assessment and appraisal process. Patients can be systematically represented in bodies that assess and appraise OMPs as part of an overarching patient association. Disease-specific patient representatives could be involved throughout the process, provided that they have received appropriate training and support to contribute fully. EUPATI (the European Patient's Academy) provides training courses for patients with the aim of enhancing their skills and enabling them to contribute to medicines research and development. Such initiatives should be supported and supplemented with process-specific training at national levels [80].

To this end, clear, consistent guidelines should be developed, enabling stakeholders (in particular patient associations), to prepare submissions and be in a position to respond to the appraisal process. For example, generic patient group submission templates, such as those developed by Health Technology Assessment International (HTAi), can help patient groups identify the type of information that HTA agencies require in regard to patient and caregiver experiences, living with the disease, its management and unmet needs [81].

Given the nature of rare diseases, uncertainty is inherent in all elements of product value. When assessing value, payers should consider this uncertainty in light of the disease prevalence and the level of existing knowledge and evidence about the disease. Typically, rare diseases with the lowest prevalence are associated with greater uncertainty compared with rare diseases with a higher prevalence [20].

At the time of launch, it should be recognised that, due to the size of the patient population and limited natural history data, there will often be incomplete information to provide certainty around the long-term clinical benefit and overall value of a new OMP [57]. In those cases there will be a need for a continuum of evidence 
PRINCIPLE 5: To accommodate uncertainty, value assessment and pricing and reimbursement decisions should be adaptive subject to the need and availability of information over time

a) Given the nature of rare diseases, there is inherent uncertainty around all elements of product value. When assessing value, payers should consider this uncertainty in light of:

- disease prevalence

- disease severity and unmet need

- amount of prior research conducted in the disease

- extent to which the manufacturer has taken reasonable steps to minimise uncertainty

b) To account for clinical and economic uncertainty, value assessment processes need to be adaptive (i.e. contingent), where necessary, and continuous rather than binary at the point of launch

c) Pricing and reimbursement decisions should allow movement both up and down with newly generated evidence on value

d) Where adaptive processes are required, all parties (payers, HTA agencies, involved HCPs, patients and industry) need to agree on this iterative process and clearly document the following:

- the evidence required and milestones for each step of the assessment - the implications of not meeting the requirements and expectations initially agreed

- each stakeholder's shared responsibility to collect and evaluate the data

e) Where possible, the collection and analysis of real-world data should be co-ordinated at a European or international level and should be integrated in disease level registries and databases:

- to obtain more European consistency in the continuous assessment and appraisal of OMPs

- to collect data on the true prevalence of a given rare disease in order to minimise financial uncertainty for payers

generation. Further data collection will often be required post-launch to enhance the understanding of the clinical benefit and the overall value and to reduce uncertainty. Systematically collecting data from registries as well as implementing managed access schemes (where possible) could help mitigate the uncertainties and fill data gaps. This need for incremental evidence generation has been recognised through conditional approval regulatory processes [82].

Value assessment processes need to be adaptive (i.e. contingent) where necessary and continuous, rather than binary at the point of launch. An adaptive value assessment process would take into account the nature of the $R \& D$ challenge in rare diseases. Furthermore, it would contribute to better access to treatments for patients and would allow the building of evidence in clinical practice. $P \& R$ decisions may also be adaptive (i.e. increased or decreased) based on the data provided. While there are precedents for adaptive $P \& R$ mechanisms in Europe, there is some scepticism about their effectiveness historically (from both payers and industry) and a need for more robust design and implementation in future $[10,83]$.

Adaptive pathways to OMP assessment have been increasingly mentioned in recent policy debates and have been piloted at the European level [84]. Where adaptive processes are required, a framework for shared agreement between stakeholders should be developed to identify key responsibilities of all parties. Data collected should be independently validated and reviewed to maintain objectivity.

There has been a trend towards payers mandating country-specific registries (e.g. Germany, UK, France) to support conditional reimbursement decisions for OMPs with different data variables collected [64]. Where possible, the collection and analysis of real-world data should be co-ordinated at a European level and should be integrated in disease level registries and databases to obtain more consistency in the continuous assessment and appraisal of OMPs. This requires common definitions of outcomes to be collected as well as uniform sets of standards to guarantee data quality and completeness. It is essential to ensure that the duties and rights of every party involved in real-world data collection are respected. Therefore, financial responsibilities for collecting registry data should be shared proportionally between interested stakeholders as per the EUCERD recommendation on rare disease patient registration [85]. There should be the option to supplement this data with additional information that may be specific to Member States. EUnetHTA has notably put in place a common core protocol for Additional Evidence Generation (AEG) to set out the methodological basis for European cooperation in this field [86].

Estimating the likely budget impact of OMPs is a key challenge for payers $[47,55]$. The greatest uncertainty in estimating budget impact concerns the number of patients who will receive treatment. This uncertainty stems from the challenges of estimating prevalence as a result of the poor diagnosis of rare disease patients and the lack of expertise in these diseases. Local prevalence data is often inadequate and there is an opportunity to reduce uncertainty through the pooling of epidemiological data at the European level. However, coherent systems are necessary to facilitate this collaboration between Member States and to allow for the co-ordination of postlaunch data collection.

In advance of product launch, manufacturers, payers, HTA agencies, centres of expertise and European reference networks should collaborate to collect data on the true prevalence of a given rare disease in order to minimise financial uncertainty for payers. Such early collaboration will also ensure development of adequate capabilities for large scale post-launch data collection.

The heterogeneous nature of rare diseases and small patient populations make it difficult to collect extensive data [57]. For ethical reasons, it may not be possible to generate data from certain subgroups of populations (e.g. children) who are often affected by rare diseases, but may not be allowed to 
participate in clinical trials [87]. Wherever possible, reimbursement decisions should seek to ensure that all patients specified in the product marketing authorisation should receive access to treatment. This should take into consideration how the uncertainty for a proportion of the population can be better addressed. This may be in the form of an adaptive pathway or managed access program.

\section{Principles 6: All eligible patients within the authorised label of an OMP should be considered in the national P\&R decision although different decisions on access may apply to different sub-populations \\ a) Wherever possible, reimbursement decisions should seek to ensure that all patients specified in the product marketing authorisation should receive access to treatment \\ b) Reimbursement may be reflective of situations where there is a broad spectrum of disease and clearly defined patient subgroups in which OMP value substantially differs}

Data usually does not allow for sub-grouping in a way that is statistically or clinically credible. However, where there is a broad spectrum of disease, and the financial impact of treatment is very high, it is reasonable to consider this in $\mathrm{P} \& \mathrm{R}$ decisions across patient subgroups.

\section{Principles on OMP sustainable funding systems}

Funding for OMPs should be co-ordinated at a national level in order to avoid disparities in access between regions and to pool the financial risk of irregular distribution of patients across geographies. Where reimbursement decisions have been left to regional bodies, variance in access has been observed (e.g. Sweden, Italy) [8, 88, 89]. Due to the genetic nature of many rare diseases, the burden of payment may be concentrated in one area; a national risk-sharing scheme would overcome regional disparities in disease presentation.

In order to facilitate this, regional and local funding bodies should liaise and cooperate with national authorities to avoid inconsistencies and inequalities in regional access. Regional funding bodies should be represented

PRINCIPLE 7: Funding should be provided at the national level to ensure patient access to OMPs

a) Funding for OMPs should be co-ordinated at a national level in order to avoid disparities in access between regions and to pool the financial risk of irregular distribution of patients

b) Regional and local funding bodies should liaise and cooperate with national authorities to avoid inconsistencies and inequalities in regional access

c) It is preferable that funding for OMPs should come out of normal healthcare budgets rather than from ear-marked rare disease funds that do not allow for a long-term perspective within national bodies, ensuring funding decisions taken at this level are quickly implemented locally.

It is preferable that funding for OMPs should come out of normal healthcare budgets as opposed to ear-marked rare disease funds that do not allow for a long-term perspective. Ear-marked disease-specific funds are seen in countries such as Scotland [90], Italy [91] or in England with the Cancer Drug Fund [92]. These tend to be subject to political revision and can be arbitrary in value.

Manufacturers, payers and HTA agencies should collaborate nationally to improve forecasting and cooperate at the European level for horizon scanning. Such collaboration should aim to help budget holders predict and plan for expenditure and ensure adequate funding of OMPs. One of the primary concerns of payers regarding OMPs is the long-term sustainability of funding $[5,17]$. To ensure funding is sustainable, payers need to model beyond annual budget cycles to forecast the total expenditure on OMPs, including likely savings as older products lose marketing exclusivity. In addition to budget impact forecasting, payers should look beyond the total expenditure on an OMP to include cost offsets from reduced medical resource use resulting from the introduction of the OMP. Manufacturers

PRINCIPLE 8: Evidence-based funding mechanisms should be developed to guarantee long-term sustainability

a) Manufacturers, payers and HTA agencies should collaborate nationally to improve forecasting and cooperate at the European level for horizon scanning with the aim of helping budget holders predict and plan for expenditure and ensure adequate funding of OMPs

b) Early stage dialogue should occur between all stakeholders to ensure long term sustainability of outcomes

should collaborate with payers in this process, providing timely information on products under development, label expansions and expected launch dates, as well as aiding in the estimation of potential cost-offsets. Horizon scanning efforts can be co-ordinated at a European level, as the core information on the number of products likely to be approved is common across European countries.

\section{Principles on OMP European co-ordination}

While recognising that the reality today is one of national level competence, there is potential for a greater level of co-ordination at the European level with regards to certain elements of value assessment. Rationales for collaboration between Member States on value assessment could include guarantees about greater consistency in the definition and assessment of clinical value, greater concentration of clinical expertise, pooling of data on epidemiology, opportunities for more systematic collection and assessment of data, and reduced duplication of effort at the national level in the re-assessment of value 
PRINCIPLE 9: In the future there should be greater co-ordination of OMP value assessment processes at a European level

a) While recognising that the reality today is one of national level competence, there is potential for a greater role for co-ordination of certain elements of value assessment in the future at European level

b) Rationales for collaboration between European Member States on value assessment could include:

- Guarantee more consistency between Member States in the definition and assessment of clinical value

- Greater concentration of clinical expertise

- Pooling of data on epidemiology

- Opportunities for more systematic collection and assessment of data

- Reduced duplication of effort at the national level in the re-assessment of value and as such, faster access to medicines for patients

c) In order to co-ordinate efforts, Member States should increasingly collaborate and share their knowledge in preparation for local evidence appraisals

d) A co-ordinated mechanism should be put in place at the European level to help reduce evidential uncertainties around OMPs and enable rapid and continuous data collection post launch

and as such, faster access to medicines for patients. The benefits of establishing European Reference networks for rare diseases has been widely recognised [93], notably by overcoming the limited experience of professionals confronted with rare disease and by improving access for EU citizens to treatment requiring a particular concentration of resources or expertise. The future European collaboration on Relative Effectiveness Assessments, which is currently launching pilots within EUNetHTA's Joint Action 3 [94] and planning to be formalised in 2019, is a key step forward towards this needed collaboration.

\section{Conclusion}

The advent of European OMP legislation and subsequent growth in new authorised treatments represents an important opportunity to improve human health and redress the years of under-investment in rare disease treatments. To be successful, this goal requires the maintenance of incentives that have stimulated investment in European rare disease research with subsequent benefits for the wider scientific economy [95]. It also requires further development of $P \& R$ processes to improve patient access to new medicines and provide greater clarity to those who would invest in future research in rare diseases.

There are many challenges to quick and comprehensive patient access to OMPs [5, 47]. In addition to the technical issues of imperfect information, evidential and financial uncertainty, evolving regulatory pathways and novel scientific platforms, are the more general concerns of lack of mutual understanding between payers and OMP manufacturers. Greater consistency of processes between Member States, clear criteria for the assessment of value and value for money, increased transparency and clarity about decisions, and more collaboration and information sharing between payers and manufacturers could help address these challenges.

The principles outlined in this paper may be helpful in drawing together an emerging consensus on this topic and identifying areas where consistency in payer approach could be achievable and beneficial. These principles recognise that $P \& R$ is a national competency, as there needs to be flexibility for payers to reflect local societal preferences. They do not seek to specify the process that payers use to make $P \& R$ decisions, but to ensure a common underlying approach and convergence around core concepts. Future research might seek to explore on a country-by-country basis the areas in which existing value assessment and $P \& R$ frameworks align with these principles and where there is divergence, as a stimulant for policy appraisal. Identifying differences between the principles and current systems will stimulate further discussions on the practical changes and ways to implement the principles.

The formulation of the principles has been informed by evidence wherever possible, but ultimately these recommendations represent the opinion and experiences of those experts involved in the development, regulation, assessment and use of OMPS in Europe. As such, they are fundamentally subjective. These principles are likely to stimulate the current debate regarding cooperation between HTA agencies in Europe, and to inspire future research to better document what can be achieved to improve a fair assessment of OMPs and a fair utilisation of this assessment by the decision-makers.

The need for greater consistency, clarity and certainty will become ever more important as the number of OMPs grows. Yet, while there are still many thousands of rare diseases for which no effective treatments exist, all stakeholders - payers, policy makers and manufacturers - will need to take a long-term perspective and build frameworks and processes that are capable of addressing the scale of the challenge. Ultimately, OMPs offer the potential to improve equity of access to effective treatment for the biologically least advantaged in our communities. All stakeholders have an obligation to work together to ensure that this promise is realised.

\section{Additional file}

Additional file 1: Glossary of terms of the guide to core elements of value presented in Fig. 3. (DOCX $121 \mathrm{~kb}$ )

\section{Abbreviations}

AEG: Additional evidence generation; ASCO: American society of clinical oncology; COMP: Committee for orphan medicinal products; EMA: European medicines agency; EPAR: European public assessment report; 
ESMO: European society for medical oncology; EU: European Union; EUnetHTA: European network on health technology assessment; EUPATI: European Patients' Academy; HCP: Healthcare professional; HRQOL: Health-related quality of life; HTA: Health technology assessment; ICER: Incremental cost-effectiveness ratio; MCDA: Multi-criteria decision analysis; MoCA-OMP: Mechanism of coordinated access to orphan medicinal products; MPS: Mucopolysaccharidosis; NICE: National Institute for Health and Care Excellence; OMP: Orphan medicinal product; P\&R: Pricing and reimbursement; PACE: Patient and clinician engagement; QALY: Quality-adjusted life year; R\&D: Research and development; TC: Teleconference; TVF: Transparent value framework

\section{Acknowledgements}

ORPH-VAL wishes to thank EURORDIS for facilitating the public consultation exercise and providing the opportunity to present the principles at the 2016 Multi-Stakeholder meeting. It would also like to thank EUCOPE and Celgene for providing support to the group, and to Judith Balvanyos and Zara Babakordi for assistance in preparation of meetings and materials.

\section{Funding}

Members of the Working Group participated on a voluntary basis and did not receive payment, other than reimbursement of travel expenses where necessary. Secretariat services and medical writing support were provided to the group funded jointly by EUCOPE and Celgene Corporation.

\section{Availability of data and materials}

All data generated or analysed during this study are included in this published article.

\section{Authors' contribution}

All authors participated in the formulation of the content of the recommendations. All authors reviewed, edited and commented on multiple iterations of the draft manuscript. All authors have read and approved the final manuscript. LA and AH were responsible for drafting the manuscript and incorporating the feedback from other authors.

\section{Authors' information}

$L A$ is Professor of Health Economics at the University of Ghent in Belgium. $S A$ is the Founder of Orphanet and is Emeritus Research Director at INSERM, France. SA is the editor-in-chief of the ORPHANET Journal of Rare Diseases and the Chair of the WHO Topical Advisory Group for Rare Diseases, the chair of the French National Committee of Registries and the chair of the National Board of Physicians for Medical Genetics. SA was the leader of the Rare Diseases Task Force (2004-2010) established by the European Commission, DG Public Health and Consumers' protection.

$Y L C$ is the chief executive officer of EURORDIS. EURORDIS is a non-governmental, pan-European alliance of patient organisations representing the voice of rare disease patients and of their families. Today, EURORDIS brings together more than 700 patient organisations across more than 60 countries.

$\mathrm{KF}$ is an Honorary Research Fellow at the University of Edinburgh, Scotland. KF has been involved in health technology assessment for the past 16 years and has a particular interest in broad assessment that takes account of all the implications of using a new health technology and new processes emerging for assessment of OMPs.

PG is Member of the Swedish parliament and Member of the Board of Nordic Council and former Chair of The Welfare Committee. PG has taken national initiatives for promoting the need of equal care, as well as creating a Network in Parliament for these issues, especially for highlighting people with Rare Diseases and patients in need of Orphan Drugs.

EN (PhD), is a Postdoctoral Research Fellow at the Centre for Research on Health and Social Care Management (CERGAS) at Bocconi University in Milan (Italy).

MR is Consultant oncologist at IRCCS San Raffaele Scientific Institute in Milan, Italy

JLR serves as the Public Affairs Director, European and International Advocacy for EURORDIS-Rare Diseases Europe. EURORDIS is a non-governmental, pan-European alliance of patient organisations representing the voice of rare disease patients and of their families. Today, EURORDIS brings together more than 700 patient organisations across more than 60 countries.
MS (MD, PhD, MBA) is Professor of Health Economics at the University of Heidelberg, Head of the Division of Health Economics at the German Cancer Research Center (DKFZ), Heidelberg/Germany, and Chairman and Scientific Director of the not-for-profit Institute for Innovation \& Valuation in Health Care, Wiesbaden/Germany.

DT is Emeritus Professor of Pharmaceutical and Public Health Policy at University College London (UK).

$C T$ is Head of Clinical Research at IRCSS San Raffaele, Rome (Italy). CT has spent 14 years serving the Italian Medicines Agency (AIFA)

JTF is Professor of Clinical Pharmacology and Therapeutics at the Autonomous University of Barcelona, Spain

$\mathrm{SU}$ is the Associate Director of the Highly Specialised Technology program at NICE in England, responsible for running the program to evaluate medicines and technologies for rare and ultra-rare conditions for use in the NHS. Prior to joining NICE, SU was responsible for commissioning rare and ultra-rare disease services in NHS England, where she delivered many improvements to these services by collaborating with industry, clinicians and patient groups. She has led nationally in the NHS for lysosomal storage disorders and delivered more efficient drug and homecare prices by running national tender exercises with the Department of Health. She also works as a James Lind Alliance adviser supporting the delivery of key priorities for research in many different non rare disease areas.

$\mathrm{AH}$ is the Founder and Director of Dolon Ltd, a healthcare consultancy company providing specialised services in the field of rare diseases and rare disease treatments

LLD is Director of European government relations and public policy at Celgene

\section{Competing interests}

LA has performed paid consultancy services for Celgene

SA has provided consultancy services for Shire and Pfizer on policy issues but not on product-related issues.

YLC does not have personal competing interests. Potential competing interests of organisation of affiliation are declared and cleared by the European Medicines Agency. All information are available on the EURORDIS website (www.eurordis.org) under the financial section.

KF has received consultancy fees from a range of pharmaceutical companies for advice relating to the assessment of pharmaceuticals and patient involvement.

PG does not have any competing interests.

EN received unrelated consulting fees and has no financial or non financial interests.

MR has received unrelated consultancy fees from Celgene, Boehringer, Helsinn, Genentech, Lilly, Merck-Serono, Baxalta, Pfizer, Novocure and Halozyme.

$J L R$ does not have any competing interests. Potential competing interests of organisation of affiliation are declared and cleared by the European Medicines Agency. All information are available on the EURORDIS website (www.eurordis.org) under the financial section.

MS currently leads the European Social Preferences Measurement (ESPM) project, which is supported under an unrestricted educational grant policy by a public health insurance association (curafutura, Bern/Switzerland), a private health insurance company (Schweizer Versicherungsverband, SW, Zurich/Switzerland), a health care provider (Galenica, Bern/Switzerland), the research-based pharmaceutical industry (Interpharma, Basel/Switzerland), BioMarin Europe Ltd. (London/England), and Genzyme Europe B.V. (Naarden/ Netherlands). He was leader of a project on the evaluation of ultra-rare disorders (URDs), which has been supported by BioMarin Europe Ltd. (London/England), and Genzyme Europe B.V. (Naarden/The Netherlands), again under an unrestricted educational grant agreement with the Institute for Innovation \& Valuation in Health Care (Wiesbaden/Germany).

DT has been indirectly in receipt of funds from organisations such as the Association of the British Pharmaceutical Industry for work on topics such as the use of cost effectiveness thresholds in pharmaceutical cost effectiveness analyses, but has at no time had any direct financial or other interests in the supply of orphan medicines or similar items. In the context of this article, DT does not have any competing interests to declare.

$C T$ does not have any competing interests.

JTF does not have any competing interests.

$\mathrm{SU}$ is a James Lind Alliance adviser who works with various groups and individuals to set agree and research priorities. This is an independent position for which she receives financial compensation to undertake. Topics 
being advised on at the time of writing the paper are: Alcohol Related Liver Disease, Teenage and Young Adult Cancer, Bleeding Disorders

AH provides paid consultancy services to pharmaceutical companies, some of whom manufacture medicines for rare diseases

LLD is a Celgene employee

\section{Consent for publication}

Not applicable.

\section{Ethics approval and consent to participate}

Not applicable.

\section{Author details}

'Department of Public Health, Ghent University, Ghent, Belgium. ${ }^{2}$ ICM, CNRS UMR 7225--Inserm U 1127--UPMC-P6 UMR S 1127, Paris, France. ${ }^{3}$ EURORDIS-Rare Diseases Europe, Paris, France. ${ }^{4}$ University of Edinburgh, Edinburgh, Scotland. ${ }^{5}$ Swedish Parliament, Stockholm, Sweden. ${ }^{6}$ Centre for Research on Health and Social Care Management (CERGAS), Bocconi University, Milan, Italy. ${ }^{7}$ IRCCS Ospedale San Raffaele Scientific Institute, Milan, Italy. ${ }^{8}$ EURORDIS-Rare Diseases Europe, Paris, France. ${ }^{9}$ Health Economics at the University of Heidelberg, Heidelberg, Germany. ${ }^{10}$ Division of Health Economics at the German Cancer Research Center (DKFZ), Heidelberg, Germany. ${ }^{11}$ Institute for Innovation \& Valuation in Health Care, Wiesbaden, Germany. ${ }^{12}$ Pharmaceutical and Public Health Policy, University College London (UCL), London, UK. ${ }^{13}$ Clinical Research at IRCSS San Raffaele, Rome, Italy. ${ }^{14}$ Clinical Pharmacology and Therapeutics, Autonomous University of Barcelona, Barcelona, Spain. ${ }^{15}$ NICE, Manchester, UK. ${ }^{16}$ Dolon Ltd, London, UK. ${ }^{17}$ European government relations and public policy at Celgene, Brussels, Belgium.

Received: 28 September 2016 Accepted: 23 February 2017 Published online: 10 March 2017

\section{References}

1. EUCERD (The European Union Committee of Experts on Rare Diseases). Recommendation of the European Union committee of experts on rare diseases to the European Commission and the Member States on improving informed decisions based on the clinical added value of orphan medicinal products (CAVOMP) information flow. 2012. http://ec. europa.eu/health/rare_diseases/docs/eucerd_cavomp_annex_en.pdf. Accessed 06 Sep 2016.

2. European Commission. Inventory of Union and Member State incentives to support research into, and the development and availability of, orphan medicinal products. 2015. http://ec.europa.eu/health/files/orphanmp/doc/ orphan_inv_cwd_20160126.pdf. Accessed 07 Sep 2016.

3. European Commission. Orphan medicinal products. 2016. http://ec europa.eu/health/human-use/orphan-medicines/index_en.htm. Accessed 06 Sep 2016

4. Dupont A, Van Wilder P. Access to orphan drugs despite poor quality of clinical evidence. Br J Clin Pharmacol. 2011;71(4):488-96.

5. Gutierrez L, Patris J, Hutchings A, Cowell W. Principles for consistent value assessment and sustainable funding of orphan drugs in Europe. Orphanet J Rare Dis. 2015;10:53.

6. Barham L. Orphan medicines: special treatment required? 2012. http:// socialwelfare.bl.uk/subject-areas/services-activity/health-services/2020health/ 147277orphan_medicines_2012.pdf. Accessed 06 Sep 2016.

7. Gammie T, Lu C, Babar ZD. Access to Orphan Drugs: A Comprehensive Review of Legislations, Regulations and Policies in 35 Countries. PLoS One. 2015;10(10):e0140002

8. Garau M, Mestre-Ferrandiz J. Access Mechanisms for Orphan Drugs: A Comparative Study of Selected European Countries. 2009. https://www.ohe. org/publications/access-mechanisms-orphan-drugs-comparative-studyselected-european-countries. Accessed 06 Sep 2016.

9. EURORDIS. Inventory of access and prices of orphan drugs across Europe: a collaborative work between National Alliances on Rare Diseases \& EURORDIS. 2010. http://img.eurordis.org/newsletter/pdf/mar-2011/ERTC_ 13122010_YLeCam_Final.pdf. Accessed 07 Sep 2016.

10. Morel T, Arickx F, Befrits G, Siviero P, van der Meijden C, Xoxi E, et al. Reconciling uncertainty of costs and outcomes with the need for access to orphan medicinal products: a comparative study of managed entry agreements across seven European countries. Orphanet J Rare Dis. 2013;8:198.
11. Van den Aardweg S. HTA of orphan drugs across six countries: fair, flawed or failing? Euro Observer. 2010;12(4):14-7.

12. Kesselheim A, Myers J, Avorn J. Characteristics of Clinical Trials to Support Approval of Orphan vs Nonorphan Drugs for Cancer. JAMA. 2011;305(22):2320-6.

13. EMA (European Medicine Agency). Orphan designation. 2016. http://www. ema.europa.eu/ema/index.jsp?curl=pages/regulation/general/general_ content_000029.jsp. Accessed 8 Dec 2016.

14. Simoens S, Picavet E, Dooms M, Cassiman D, Morel T. Cost-effectiveness assessment of orphan drugs: a scientific and political conundrum. Appl Health Econ Health Policy. 2013;11:1-3.

15. Drummond L, Towse A. Orphan drugs policies: a suitable case for treatment. Eur J Health Econ. 2014;15:335-40.

16. Schey C, Milanova T, Hutchings A. Estimating the budget impact of orphan medicines in Europe: 2010-2020. Orphanet J Rare Dis. 2011;6:62.

17. Rollet $P$, Lemoine $A$, Dunoyer $M$. Sustainable rare diseases business and drug access: no time for misconceptions. Orphanet J Rare Dis. 2013;8:109.

18. Tordrup D, Tzouma V, Kanavos P. Orphan drug considerations in Health Technology Assessment in eight European countries. Rare Diseases and Orphan Drugs: An International Journal of Public Health. 2014;1 (3):86-97.

19. Australian Government - Department of Health. Life saving drugs program criteria and conditions. 2016. http://www.health.gov.au/internet/main/ publishing.nsf/Content/lsdp-criteria. Accessed 16 Sep 2016.

20. Nicod E. Why do health technology assessment coverage recommendations for the same drugs differ across settings? Applying a mixed methods framework to systematically compare orphan drug decisions in four European countries. Eur J Health Econ. 2016 [Epub ahead of print].

21. Sussex J, Rollet P, Garau M, Schmitt C, Kent A, Hutchings A. Multi-Criteria Decision Analysis to Value Orphan Medicines. 2013. https://www.ohe.org/ publications/multi-criteria-decision-analysis-value-orphan-medicines. Accessed 06 Sep 2016.

22. Krüger L, Tamminga J, Wijnen B, Hiligsmann M, Evers S. An European overview of the future changes in evidence requirements for the reimbursement of orphan drugs A stakeholder analysis. Value Health. 2014; 17(3):A236. https://www.ispor.org/research_pdfs/46/pdffiles/PSY72.pdf.

23. Grubert N. How will the Pharmadialog change the AMNOG and market access in Germany? 2016. https://www.linkedin.com/pulse/howpharmadialog-change-amnog-market-access-germany-neil-grubert. Accessed 08 Sep 2016

24. Palaska C, Hutchings A. Value Assessment and Pricing Frameworks for Rare Disease Treatments: New Approaches From The Literature. Value Health. 2015:18(7):A678

25. European Commission. Transparent value framework (Platform on access to medicines in Europe - Working Group on Mechanism of coordinated access to orphan medicinal products). 2014. http://ec.europa.eu/DocsRoom/ documents/7631?locale=fr. Accessed 14 Sep 2016.

26. Hughes-Wilson W, Palma A, Schuurman A, Simoens S. Paying for the Orphan Drug System: break or bend? Is it time for a new evaluation system for payers in Europe to take account of new rare disease treatments? Orphanet J Rare Dis. 2012;7:74.

27. Fedyaeva V, Omelyanovskiy V, Rebrova O, Khan NN, Petrovskaya E. MCDA approach to ranking rare diseases in Russia: preliminary results. Value Health. 2014;17(7):A539.

28. Schey C, Connolly M. Multi-criteria decision analysis (MCDA): testing a proposed MCDA framework for orphan drugs. Value Health. 2014:17(7):A556.

29. Paulden M, Stafinski T, Menon D, McCabe C. Value-Based Reimbursement Decisions for Orphan Drugs: A Scoping Review and Decision Framework. Pharmacoeconomics. 2015;33:255-69.

30. Wagner M, Khoury H, Willet J, Rindress D, Goetghebeur M. Can the EVIDEM Framework Tackle Issues Raised by Evaluating Treatments for Rare Diseases: Analysis of Issues and Policies, and Context-Specific Adaptation. Pharmacoeconomics. 2016;34:285-301.

31. Kanavos P, Angelis A. Multiple Criteria Decision Analysis for Value Based Assessment of New Medical Technologies: A Conceptual Framework. 2013. http://eprints.Ise.ac.uk/51211/. Accessed 20 Sep 2016.

32. Endrei D, Molics B, Ágoston I. ulticriteria Decision Analysis in the Reimbursement of New Medical Technologies: Real-World Experiences from Hungary. Value Health. 2014;17(4):487-9.

33. Williams $\mathrm{P}$, Mauskopf J, Lebiecki J, Kilburg A. Using multicriteria decision analysis during drug development to predict reimbursement decisions. J Mark Access Health Policy. 2014. doi:10.3402/jmahp.v2.25270. 
34. Wahlster P, Goetghebeur M, Schaller S, Kriza C, Kolominsky-Rabas P, EMN' NLECMT'V. Exploring the perspectives and preferences for HTA across German healthcare stakeholders using a multi-criteria assessment of a pulmonary heart sensor as a case study. Health Res Policy Syst. 2015;13:24.

35. Cherny N, Dafni UKJ, Sobrero A, Zielinski C, de Vries E, Piccart M. A standardised, generic, validated approach to stratify the magnitude of clinical benefit that can be anticipated from anti-cancer therapies: the European Society for Medical Oncology Magnitude of Clinical Benefit Scale (ESMO-MCBS). Ann Oncol. 2015;26:1547-73.

36. Schnipper L, Davidson N, Wollins D, Tyne C, Blayney D, Blum D, et al. American Society of Clinical Oncology Statement: A Conceptual Framework to Assess the Value of Cancer Treatment Options. J Clin Oncol. 2015:33(23):2563-77.

37. EURORDIS. The Voice of 12,000 Patients: Experiences and Expectations of Rare Disease Patients on Diagnosis and Care in Europe. 2009. http://www. eurordis.org/IMG/pdf/voice_12000_patients/EURORDISCARE_FULLBOOKr.pdf. Accessed 06 Sep 2016.

38. de Vrueh R, Baekelandt E, de Haan J. World Health Organisation update on 2004 Background Paper, BP 6.19 Rare Diseases. 2013. http://www.who.int/ medicines/areas/priority_medicines/BP6_19Rare.pdf. Accessed 08 Sep 2016.

39. Schieppati A, Henter Jl, Daina E, Aperia A. Why rare diseases are an important medical and social issue. Lancet. 2008;371:2039-41.

40. EUCERD (The European Union Committee of Experts on Rare Diseases). Rare Diseases: addressing the need for specialised social services and integration into social policies. 2012. http://www.eucerd.eu/wp-content/uploads/2013/ 03/EJA_Specialised_Social_Services_Paper.pdf. Accessed 06 Sep 2016.

41. Mazzucato M, Visonà Dalla Pozza L, Manea S, Minichiello C, Facchin P. A population-based registry as a source of health indicators for rare diseases: the ten-year experience of the Veneto Region's rare diseases registry. Orphanet J Rare Dis. 2014;9:37.

42. EUCERD (The European Union Committee of Experts on Rare Diseases). Report on EUCERD guiding principles for social care in RD/draft of Expert Group Recommendations in the social field. 2015. http://www.eucerd.eu/ wp-content/uploads/2016/03/EJADeliverable7.pdf. Accessed 06 Sep 2016.

43. Paris V, Belloni A. Value in Pharmaceutical Pricing. OECD Health Working Papers. 2013. doi:10.1787/5k43jc9v6knx-en.

44. Schlander M, Garattini S, Holm S, Kolominsky-Rabas P, Nord E, Persson U, et al. Incremental cost per quality-adjusted life year gained? The need for alternative methods to evaluate medical interventions for ultra-rare disorders. J Comp Eff Res. 2014;3(4):399-422.

45. Whitty J, Lancsar E, Rixon K, Golenko X, Ratcliffe J. A systematic review of stated preference studies reporting public preferences for healthcare priority setting. Patient. 2014;7(4):365-86.

46. European Commission. Transparency Directive (Council Directive 89/105/ EEC). 1989. https://ec.europa.eu/growth/sectors/healthcare/competitiveness/ products-pricing-reimbursement/transparency-directive_en. Accessed 06 Sep 2016.

47. Simoens S. Pricing and reimbursement of orphan drugs: the need for more transparency. Orphanet J Rare Dis. 2011;6:42.

48. Douglas M, Wilcox E, Burgess M, Lynd L. Why orphan drug coverage reimbursement decision-making needs patient and public involvement. Health Policy. 2015;119(5):588-96.

49. Solon C, Kanavos P. An analysis of HTA decisions for orphan drugs in Canada and Australia. Working Paper No: 42. 2015. http://www.lse.ac.uk/ LSEHealthAndSocialCare/pdf/LSEHealthworkingpaperseries/LSEHWP42.pdf. Accessed 08 Sep 2016.

50. Hughes D, Tunnage B, Yeo S. Drugs for exceptionally rare diseases: do they deserve special status for funding? QJM. 2005;98:829-36.

51. Farrugia A, O'Mahony B, Cassar J. Health technology assessment and haemophilia. Haemophilia. 2012;18:152-7.

52. Lantrès $\mathrm{O}$. Pricing and Reimbursement of Medicinal Products in France. 2013. http://www.eucope.org/en/files/2013/03/Lantr\%C3\%A8sPricing-and-Reimbursement-of-Medicinal-Products-in-France.pdf. Accessed 06 Sep 2016.

53. GKV-spitzenverband (German Federation of Health Insurance Funds). AMNOG - evaluation of new pharmaceutical. 2016. https://www.gkvspitzenverband.de/english/statutory_health_insurance/amnog_evaluation_ of_new_pharmaceutical/amnog_english.jsp. Accessed 06 Sep 2016.

54. Drummond M, Wilson D, Kanavos P, Ubel P, Rovira J. Assessing the economic challenges posed by orphan drugs. Int J Technol Assess Health Care. 2007;23(1):36-42.
55. Denis A, Mergaert L, Fostier C, Cleemput I, Simoens S. A comparative study of European rare disease and orphan drug markets. Health Policy. 2010;97(2-3):173-9.

56. Schlander M, Holm S, Nord E, Richardson J, Garattini S, Kolominsky-Rabas P, et al. Discussion Paper N³1. Position Paper: Towards Social Cost Value Analysis: The Need for New Approaches for Evaluating Drugs for Ultra-Rare Diseases (URDs). 2015. http://www.innoval-hc.com/discussion-papers.html. Accessed 06 Sep 2016.

57. Vickers P. Challenges and opportunities in the treatment of rare diseases. 2013. http:/www.ddw-online.com/therapeutics/p211490-challenges-and-opportunitiesin-the-treatment-of-rare-diseases-spring-13.html. Accessed 08 Sep 2016.

58. Sharma A, Jacob A, Tandon M, Kumar D. Orphan drug: Development trends and strategies. J Pharm Bioallied Sci. 2010;2(4):290-9.

59. NICE (The National Institute for Health and Care Excellence, England). Highly specialised technologies guidance. 2016. https://www.nice.org.uk/about/ what-we-do/our-programmes/nice-guidance/nice-highly-specialisedtechnologies-guidance. Accessed 06 Sep 2016.

60. Onakpoya I, Spencer E, Thompson M, Heneghan C. Effectiveness, safety and costs of orphan drugs: an evidence-based review. BMJ Open. 2015;5:e007199.

61. NICE (The National Institute for Health and Care Excellence, England). Citizens council reports: ultra orphan drugs. 2004. https://www.nice.org.uk/ Media/Default/Get-involved/Citizens-Council/Reports/ CCReport04UltraOrphanDrugs.pdf. Accessed 19 Dec 2016.

62. Desser A, Gyrd-Hansen D, Olsen J, Grepperud S, Kristiansen I. Societal views on orphan drugs: cross sectional survey of Norwegians aged 40 to 67. BMJ. 2010;341:c4715.

63. Liney W, Hughes D. Societal views on NICE, cancer drugs fund and valuebased pricing criteria for prioritising medicines: a cross sectional survey of 4118 adults in Great Britain. Health Econ. 2013;8(22):948-64.

64. WHO (World Health Organization). Access to new medicines in Europe: technical review of policy initiatives and opportunities for collaboration and research. 2015. http://www.euro.who.int/en/health-topics/Health-systems/ health-technologies-and-medicines/publications/2015/access-to-newmedicines-in-europe-technical-review-of-policy-initiatives-and-opportunitiesfor-collaboration-and-research-2015. Accessed 04 Sep 2016.

65. EUR-Lex Access to European Union law. Council Recommendation of 8 June 2009 on an action in the field of rare diseases (2009/C 151/02). 2009 http://eur-lex.europa.eu/LexUriServ/LexUriServ.do?uri=OJ:C:2009:151:0007: 0010:EN:PDF. Accessed 09 Sep 2016.

66. Facey K. Patient involvement in HTA: What added value? Pharmaceuticals Policy and Law. 2011;13(3-4):245-51.

67. Gasson S, Bliss J, Jamal-Hanjani M, Krebs M, Swanton C, Wilcox M. The Value of Patient and Public Involvement in Trial Design and Development. Clin Oncol (R Coll Radiol). 2015;27(12):747-9.

68. Berglas S, Jutai L, MacKean G, Weeks L. Patients' perspectives can be integrated in health technology assessments: an exploratory analysis of CADTH Common Drug Review. Res Involv Engagem. 2016;2:21.

69. Staley K, Doherty C. It's not evidence, it's insight: bringing patients' perspectives into health technology appraisal at NICE. Res Involv Engagem. 2016;2:4.

70. NICE (The National Institute for Health and Care Excellence, England). Patient and public involvement policy. 2016. https://www.nice.org.uk/about/ nice-communities/public-involvement/patient-and-public-involvementpolicy. Accessed 07 Sep 2016.

71. EUPATI (The European Patients' Academy). Patient involvement in the HTA decision-making process. 2016. https://www.eupati.eu/health-technologyassessment/patient-involvement-in-the-hta-decision-making-process/. Accessed 07 Sep 2016.

72. Griggs R, Batshaw M, Dunkle M, Gopal-Srivastava R, Kaye E, Krischer J, et al. Clinical research for rare disease: Opportunities, challenges, and solutions. Mol Genet Metab. 2009;96(1):20-6.

73. Augustine E, Adams H, Mink J. Clinical Trials in Rare Disease: Challenges and Opportunities. J Child Neurol. 2013;28(9):1142-50.

74. Mullins D, Vandigo J, Zheng Z, Wicks P. Patient-Centeredness in the Design of Clinical Trials. Value Health. 2014;17(4):471-5.

75. Potter B, Khangura S, Tingley K, Chakraborty P, Little J. Translating raredisease therapies into improved care for patients and families: what are the right outcomes, designs, and engagement approaches in health-systems research. Genet Med. 2016;18(2):117-23.

76. Facey K, Granados A, Guyatt G, Kent A, Shah N, van der Wilt G, et al. Generating health technology assessment evidence for rare diseases. Int J Technol Assess Health Care. 2014;30(4):416-22. 
77. IRDiRC-EMA (The International Rare Diseases Research Consortium and European Medicine Agency). Preparatory Document for Joint Workshop on Small Population Clinical Trials Challenges in the Field of Rare Diseases (DRAFT). 2016. http://www.irdirc.org/wp-content/uploads/2016/01/SPCT_ DraftDocument.pdf. Accessed 09 Sep 2016.

78. NICE (The National Institute for Health and Care Excellence, England). Elosulfase alfa for treating mucopolysaccharidosis type IVA. Response to consultee and commentator comments on the draft remit, draft scope (pre-referral) and provisional matrix. 2014. https:/www.nice.org.uk/guidance/HST2/documents/ mucopolysaccharidosis-type-iva-elosulfase-alfa-id7449. Accessed 20 Sep 2016.

79. NICE (The National Institute for Health and Care Excellence, England). Eculizumab for treating atypical haemolytic uraemic syndrome. 2015. https://www.nice.org.uk/guidance/hst1. Accessed 08 Sep 2016.

80. EUPATI (The European Patients' Academy). What is EUPATI? 2016. https:// www.eupati.eu/what-is-eupati. Accessed 08 Dec 2016.

81. HTAi (Health Technology Assessment International). For patients and patient groups. 2016. http://www.htai.org/interest-groups/patient-andcitizen-involvement/resources/for-patients-and-patient-groups.html. Accessed 15 Sep 2016.

82. EMA (European Medicine Agency). CHMP Guideline on the scientific application and the practical arrangements necessary to implement EC 507/ 2006 on the conditional marketing authorisation for medicinal products for human use falling within the scope of EC 726/2004. 2006. http://www.ema. europa.eu/docs/en_GB/document_library/Scientific_guideline/2009/10/ WC500004908.pdf. Accessed 04 Sep 2016.

83. Ferrario A, Kanavos P. Managed entry agreements for pharmaceuticals: the European experience. 2013. http://eprints.Ise.ac.uk/50513/1/_Libfile_ repository_Content_Ferrario,\%20A_Ferrario_Managed_\%20entry_ \%20agreements_2013_Ferrario_Managed_\%20entry_\%20agreements_2013. pdf. Accessed 19 Dec 2016

84. EMA (European Medicine Agency). Adaptive pathways. 2016. http://www. ema.europa.eu/ema/index.jsp?curl=pages/regulation/general/general_ content_000601.jsp\&mid=WC0b01ac05807d58ce. Accessed 09 Sep 2016

85. EUCERD (The European Union Committee of Experts on Rare Diseases). EUCERD core recommendations on rare disease patient registration and data collection. 2013. http://www.eucerd.eu/wp-content/uploads/2013/06/ EUCERD_Recommendations_RDRegistryDataCollection_adopted.pdf. Accessed 19 Dec 2016.

86. EUnetHTA (European Network for Health Technology Assessment). Evidence Generation - on the road to standardisation along the life-cycle of health technology. 2016. http://www.eunethta.eu/news/evidence-generation-roadstandardisation-along-life-cycle-health-technology. Accessed 09 Sep 2016.

87. Field M, Berman R. The Ethical Conduct of Clinical Research Involving Children. 1st ed. Washington: The National Academies Press; 2004

88. Simon K, Partners Healthcare Insights. Beyond AIFA: Navigating the next phase of Italian market access negotiations. 2013. https://www.simonkucher.com/sites/default/files/hci_fall2013_volumevii_issue3.pdf. Accessed 02 Sep 2016.

89. Jönsson B, Wilking N. New cancer drugs in Sweden: Assessment, implementation and access. J Cancer Policy. 2014;2:45-62.

90. Adams B. Scotland creates fund for rare diseases. 2013. http://www. pharmatimes.com/news/scotland_creates_fund_for_rare_diseases_1004243. Accessed 09 Sep 2016.

91. AIFA (Italian Medicines Agency). The independent research on drugs. 2016. http://www.agenziafarmaco.gov.it/en/content/independent-research-drugs. Accessed 09 Sep 2016.

92. NHS England Cancer Drugs Fund Tram. Appraisal and Funding of Cancer Drugs from July 2016 (including the new Cancer Drug Fund). A new deal for patients, taxpayers and industry. 2016. https://www.england.nhs.uk/wpcontent/uploads/2013/04/cdf-sop.pdf. Accessed 19 Dec 2016.

93. Rare Disease Task Force. Centre of References for rare diseases in Europe: State-of-the-art in 2006 and recommendations of the Rare Disease Task Force. 2006. http://ec.europa.eu/health/archive/ph_threats/non_com/docs/ contribution_policy.pdf. Accessed 20 Sep 2016.

94. Kleijnen S, Toenders W, de Groot F, Huic M, George E, Wieseler B, et al. European collaboration on relative effectiveness assessments: What is needed to be successful? Health Policy. 2015;119(5):569-76.

95. Mestre-Ferrandiz J, Garau M, O'Neill P, Sussex J. Assessment of the Impact of Orphan Medicinal Products on the European Economy and Society. 2010. https://www.ohe.org/publications/assessment-impact-orphan-medicinalproducts-european-economy-and-society. Accessed 19 Dec 2016.

\section{Submit your next manuscript to BioMed Central and we will help you at every step:}

- We accept pre-submission inquiries

- Our selector tool helps you to find the most relevant journal

- We provide round the clock customer support

- Convenient online submission

- Thorough peer review

- Inclusion in PubMed and all major indexing services

- Maximum visibility for your research

Submit your manuscript at www.biomedcentral.com/submit
O) Biomed Central 